\title{
PEMBERDAYAAN ANAK JALANAN DI KAWASAN TANJUNG PRIOK JAKARTA MELALUI PROGRAM CSR 5R++ (REDUCE, REUSE, RECYCLE, RESALE, RESHARE) PT PERTAMINA HULU ENERGI
}

\author{
Dewi Winarni Susyanti ${ }^{1}$ dan Suhail Elvari \\ Jurusan Administrasi Niaga Politeknik Negeri Jakarta \\ Email:1dewiwinarnisusyanti@gmail.com
}

\begin{abstract}
The biggest issue that occurs in Jakarta area, especially North Jakarta, is the large number of vagrant kids, there are around 87 people. The faced issue by the vagrant kids is having no place to live, having no income and often disrupting public convenient due to unmannered behavior. Moreover, some of them have committed crimes. For this reason, vagrant kids need a place to develop into a better human being. Therefore, PT Pertamina Hulu Energi Offshore NorthWest Java (ONWJ), as a business entity which maintained by the state, also runs CSR programs as a form of awareness of government regulations and concern for the communities around the area of operation. Various programs related to 5R ++ (Reduce, Reuse, Recycle, Resale, Reshare) are implemented as an effort to empower vagrant kids while utilizing the environmental waste in form of paper, that can be recycled.
\end{abstract}

Keywords: CSR, 5R ++, entity, container, waste

\section{Abstrak}

Permasalahan terbesar yang terjadi di wilayah Jakarta khususnya Jakarta Utara adalah banyaknya jumlah anak jalanan, yakni sekitar 87 orang. Permasalahan yang dihadapi anak jalanan antara lain mereka tidak mempunyai tempat tinggal, tidak memiliki penghasilan yang tetap dan seringkali mengganggu kenyamanan publik karena tingkah laku yang kurang santun bahkan beberapa dari mereka sudah melakukan tindak kriminal. Untuk itu anak jalanan ini perlu sebuah wadah untuk dapat berkembang menjadi manusia yang lebih baik. Oleh karena itu PT Pertamina Hulu Energi Offshore NorthWest Java (ONWJ), sebagai sebuah entitas bisnis yang dinaungi oleh negara turut menjalankan program CSR sebagai bentuk kesadaran akan peraturan pemerintah serta kepedulian terhadap masyarakat di sekitar wilayah operasi. Berbagai program terkait 5R++ (Reduce, Reuse, Recycle, Resale, Reshare) dilaksanakan sebagai upaya memberdayakan anak jalanan sekaligus memanfaatkan limbah lingkungan berupa kertas yang bisa didaur ulang.

Kata kunci : CSR, 5R++, entitas, wadah, limbah

\section{PENDAHULUAN}

Peraturan yang mengatur tentang Corporate Social Responsibility (CSR) adalah Undang-Undang No. 32 Tahun 2009 mengenai Perlindungan dan Pengelolaan Lingkungan Hidup. Dalam hal ini CSR bertanggung jawab terhadap seluruh aspek yang terkait dengan masyarakat di sekitar perusahaan.
PT Pertamina Hulu Energi Offshore NorthWest Java (ONWJ), yang dinaungi oleh negara turut menjalankan program CSR sebagai bentuk kesadaran akan peraturan pemerintah serta kepedulian terhadap masyarakat di sekitar wilayah operasi. Di wilayah Tanjung Priok Jakarta merupakan wilayah operasi Pertamina Hulu Energi ONWJ, dalam melaksanakan program CSR. Menurut website resmi Pemerintah Provinsi DKI Jakarta, 
permasalahan terbesar yang terjadi di Jakarta Utara adalah banyaknya jumlah anak jalanan yaitu sejumlah 87 orang. Permasalahan yang dihadapi anak jalanan antara lain mereka tidak mempunyai tempat tinggal, tidak memiliki penghasilan yang tetap dan seringkali mengganggu kenyamanan publik karena tingkah laku yang kurang santun bahkan beberapa dari mereka sudah melakukan tindak kriminal.

Selain permasalahan anak jalanan, Pertamina Hulu Energi ONWJ memiliki permasalahan akan limbah sampah yang cukup besar yaitu mencapai 1008,6 kg/bulannya. Untuk itu, diciptakanlah sebuah program CSR untuk memberdayakan anak jalanan dan juga untuk memanfaatkan limbah kertas yaitu program CSR 5R++ .

\section{Perumusan Masalah}

Adapun rumusan masalahnya adalah bagaimana pelaksanaan program CSR 5R++ dalam memberdayakan anak jalanan di kawasan Tanjung Priok, serta hambatan yang dihadapi dan solusinya dalam menjalankan program tersebut.

\section{METODE PENELITIAN}

Pengumpulan data dan informasi yang dilakukan melalui:

a. Metode Observasi Partisipatif, dengan melakukan survey dan pengamatan secara langsung, serta kegiatan bersama untuk mendapatkan data dan informasi yang dibutuhkan mengenai standar operasional prosedur pelaksanaan program CSR $5++$.

b. Metode Wawancara, dengan mengajukan pertanyaan kepada pejabat terkait mengenai pelaksanaan program CSR 5++.

c. Metode Dokumentasi, dengan mengumpulkan data-data, informasi, dan referensi seperti, foto, dokumen, dan laporan kegiatan pelaksanaan program CSR 5++.

\section{Landasan Teori}

Melalui program Corporate Social Responsibility (CSR), sebuah perusahaan memberi manfaat bagi masyarakat dan meningkatkan citranya. Kegiatan CSR dapat membantu membentuk ikatan yang lebih kuat antara perusahaan dengan masyarakat. Ikatan yang kuat antara perusahaan dengan masyarakat inilah yang menciptakan citra positif bagi perusahaan yang berdampak pada lancarnya proses operasi perusahaan.

Bowem dalam Mardikanto (2014:86) mendefinisikan CSR sebagai kewajiban pengusaha untuk merumuskan kebijakan, membuat keputusan, atau mengikuti garis tindakan yang diinginkan dalam hal tujuan dan nilai-nilai masyarakat.

Menurut David yang dikutip Hadi (2011:59) mengurai prinsip-prinsip tanggung jawab sosial (social responsibility) menjadi tiga, adalah: 1) Sustainability, adalah berkaitan dengan bagaimana perusahaan dalam melakukan aktivitas (action) tetap memperhitungkan keberlanjutan sumberdaya di masa depan. 2) Accountability, adalah upaya perusahaan terbuka dan bertanggungjawab atas aktivitas yang telah dilakukan. Akuntabilitas dapat dijadikan sebagai media bagi perusahaan membangun image dan network terhadap para pemangku kepentingan. 3) Transparancy, merupakan prinsip penting bagi pihak eksternal. Transparansi bersinggungan dengan pelaporan aktivitas perusahaan berikut dampak terhadap pihak eksternal. Di samping itu untuk mengurangi kesalahpahaman, khususnya informasi dan pertanggungjawaban berbagai dampak dari lingkungan.

\section{HASIL DAN PEMBAHASAN}

Pelaksanaan Program 5R++ dalam Memberdayakan Anak Jalanan di Kawasan Tanjung Priok merupakan program pengentasan dan pemberdayaan anak-anak jalanan di Tanjung Priok, Jakarta Utara melalui kegiatan ekonomi 
kreatif berupa daur ulang kertas dan kayu bekas menjadi kerajinan tangan yang layak dijual. Anak-anak jalanan tersebut kemudian dilatih menjadi trainer untuk mengajarkan keterampilannya ke berbagai instansi dan masyarakat luas di seluruh Indonesia.

Permasalahan limbah kertas yang belum dimanfaatkan secara optimal mencapai rata-rata 1.008,6 kg/bulan. Di samping itu permasalahan sosial, dimana sekitar 204 warga Jakarta Utara belum memiliki kesejahteraan sosial yang memadai, dan permasalahan anak jalanan berjumlah 87 orang.

Konsep utama dari Program Pengelolaan Sampah Non-B3 oleh Anak Jalanan ini adalah konsep 5R ++ yang merupakan pengembangan dari konsep 3R yaitu Reduce, Reuse, dan Recycle yang ditambahkan lagi dengan 2R yaitu Resale dan Reshare melalui program pelatihan daur ulang dan penjualan produk ekonomi kreatif.

Program ini dijalankan di Kelurahan Sungaibambu, Kecamatan Tanjung Priok, Jakarta Utara dengan sasaran anak jalanan di sekitar wilayah operasi PHE ONWJ. Tujuan program ini yaitu membantu pemerintah dalam mengatasi kesenjangan sosial anak jalanan dengan cara meningkatkan keterampilan pengelolaan daur ulang sampah menjadi produk yang bernilai ekonomis.

Di dalam Program 5R++ oleh Anak Jalanan terdapat 5 kegiatan utama:

1. Pengelolaan Limbah Kertas

1) Peningkatan Kapasitas

Kelembagaan \& Keterampilan dilakukan dengan pelatihan pembuatan limbah kertas daur ulang. Permasalahan limbah kertas yang belum dimanfaatkan secara optimal mencapai rata-rata 1.008,6 kg/bulan.

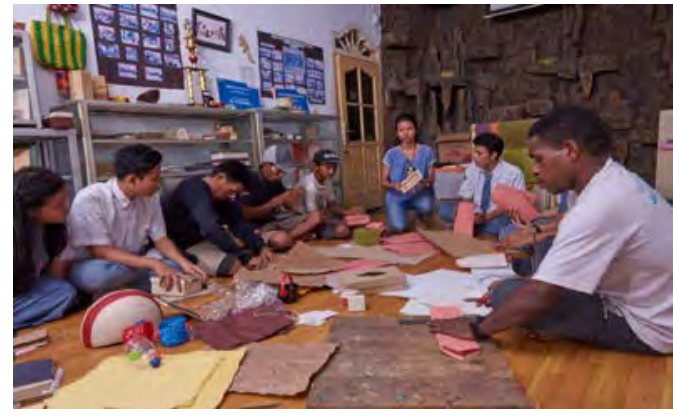

Gambar 1. Pelatihan Pembuatan Limbah Kertas Daur Ulang (Sumber: PT Pertamina Hulu Energi ONWJ, 2018)

2) Pendampingan Proses dan Desain Produksi Sesuai Pasar.

Dilakukan dengan melakukan penyempurnaan proses produksi yang terkait dengan produksi bersih, yaitu optimalisasi penggunaan air sehingga dapat mendukung konservasi air di lingkungan sekitar.

3) Pemasaran Produk Ekonomi

Kreatif

Kegiatan pemasaran yang dilakukan dengan membuka stand dalam expo yang dihelat oleh USAID dan OXFAM dalam event WASH \& Market Project Learning Review dan Pameran di Hotel Arvaduta, Jakarta

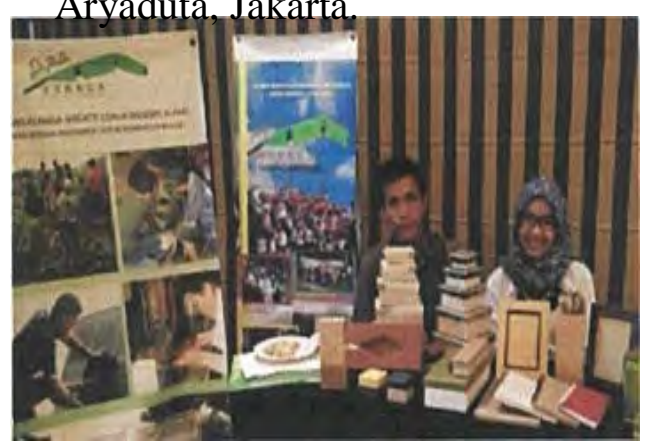

Gambar 2. Pameran Produksi (Sumber: PT Pertamina Hulu Energi, 2018)

4) Peningkatan Sarana Prasarana Operasional Pendukung.

Kegiatan tersebut antara lain penyediaan kelengkapan instalasi pengolahan air, perbaikan aula dan tempat produksi, produksi alat pembuatan bubur kertas, dan 
modifikasi mesin press manual menjadi tenaga hidrolik

2. Diseminasi Keterampilan Daur Ulang.

1) Pelatihan Daur Ulang \& Produk Ekonomi Kreatif.

Diseminasi keterampilan daur ulang dilakukan agar keterampilan yang dimiliki oleh anak binaan dapat terus bermanfaat.

2) Pemasaran Jasa Pelatihan dan Pemantauan.

Dilakukan agar kemampuan daur ulang dapat terus disebarluaskan. Pemasaran jasa pelatihan dilakukan bersamaan dengan Program Pemasaran Produk Ekonomi Kreatif.

3) Pembangunan Sarana Etalase Program di Kapal Kehati Greenthink.

Sarana etalase ini dibangun pada lahan seluas 2,5 hektar yang dibangun dengan fasilitas Hutan Pendidikan di Desa Cilamaya, Kecamatan Blanakan, Subang. Etalase ini dibangun dalam rangka memamerkan produk dan program. Etalase ini dibangun dengan bantuan alumni binaan yang telah mandiri dan bekerja sebagai pengrajin kayu di Bandung, Jawa Barat.

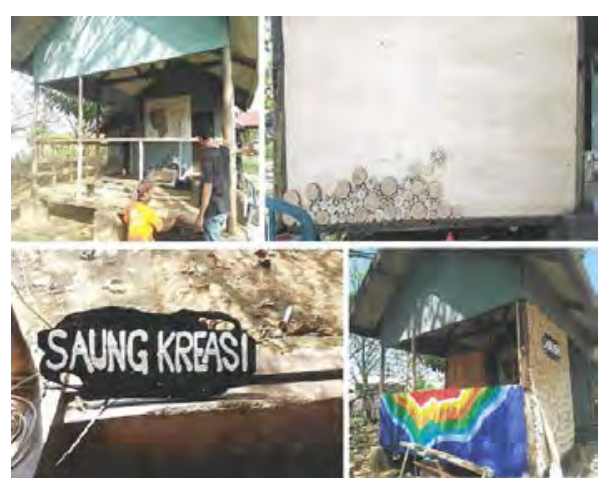

Gambar 3. Etalase Saung Kreasi (Sumber: PT Pertamina Hulu Energi ONWJ, 2018)

3. Jaminan Kualitas Produk dan Perlindungan Hak Kekayaan Intelektual
1) Penyusunan Dokumen Spesifikasi Mesin dan Pengurusan Hak Paten Merupakan pengajuan hak paten atas inovasi berupa Alat Pembuatan Bubur Kertas ke Dirjen Kekayaan Intelektual, Kemenkum HAM RI. Lalu, pada 21 April 2017, telah terbit Paten dengan Nomor IDS 000001561 atas penemuan Alat Pembuatan Bubur Kertas.

4. Bank Sampah

Bank sampah dibuat dengan tujuan dapat mengelola sampah yang mempunyai nilai ekonomis menjadi produk yang mampu memenuhi kebutuhan masyarakat.

1) Inisiasi Bank Sampah

Inisiasi bank sampah dilakukan di beberapa sekolah di kawasan Tanjung Priok. Kegiatan pemilahan dan pengumpulan sampah khususnya sampah di sekolah dengan harapan para siswa-siswi dapat menjadi nasabah di bank sampah.

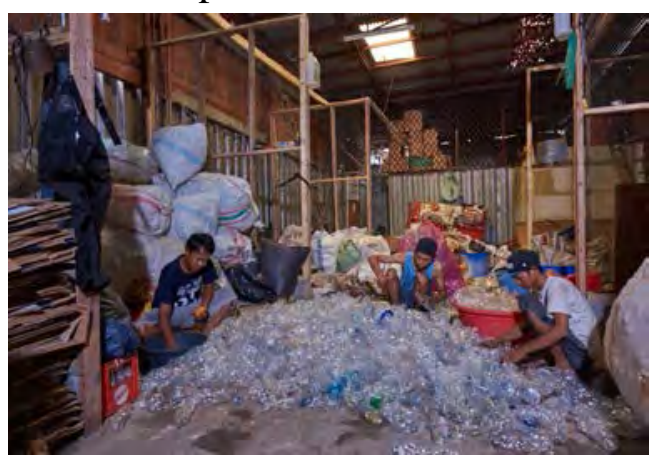

Gambar 3. Bank Sampah Kumala (Sumber: PT Pertamina Hulu Energi, 2018)

2) Peningkatan Sarana Prasarana Dalam rangka mendukung proses pengelolaan sampah, maka peningkatan sarana prasarana perlu dilakukan misalnya dengan pembuatan kamar mandi, pembelian kasur bambu sebanyak 4 buah dan juga pembelian perabotan seperti meja, kursi dan lemari.

5. Kajian Publikasi dan Dokumentasi

1) Kajian Evaluasi SROI 
Kajian evaluasi Social Return on Investment (SROI) dilakukan melalui pendekatan partisipatif yang mampu menerjemahkan dampak yang ditimbulkan dari suatu kegiatan yang dilakukan oleh suatu lembaga ataupun kegiatan CSR perusahaan. Adapun perhitungan dilakukan dengan mix method yaitu dengan metode kualitatif dan kuantitatif, melalui pendekatan studi kasus.

2) Buku Success Story

Bertepatan dengan peringatan Hari Anak Nasional. Pada 20 Agustus 2017 PHE ONWJ menyusun sebuah buku dengan konsep features yang berjudul "Metamorfosis Anak Jalanan: Harapan yang Tak Pernah Padam”.

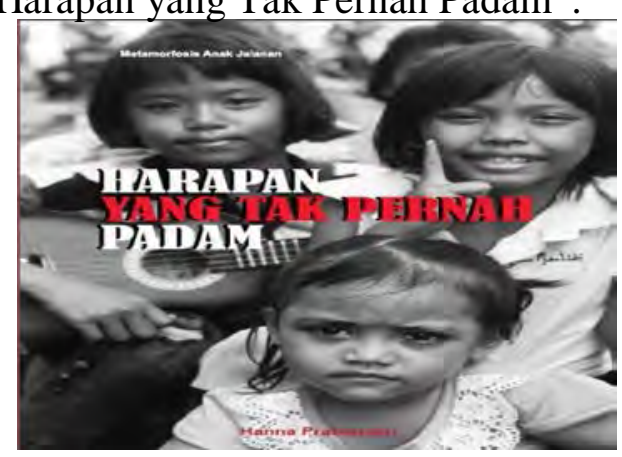

Gambar 4. Buku Success Story

"Harapan yang Tak Pernah Padam” (Sumber: PT Pertamina Hulu Energi,2018)

Hasil yang telah dicapai adalah:

a. Lebih dari dari 25 jenis produk ekonomi kreatif telah dihasilkan seperti wallpaper, bingkai, vas, tas, dan lain sebagainya dengan bahan baku varian lebih dari 100 jenis kertas seni daur ulang

b. Lebih dari 25 anak jalanan telah dikembangkan kapasitasnya untuk menjadi trainer daur ulang yang telah mendukung pencapaian 4 sekolah Adiwiyata Nasional dan 1 sekolah Adiwiyata Mandiri.

c. Bank Sampah Kumala di Tanjung Priok yang mulai dirintis pada pertengahan 2016. Saat ini telah memiliki lebih dari 156 nasabah perseorangan, 6 nasabah perusahaan, dengan turut mengelola sampah setidaknya 1,2 ton setiap bulannya.

d. Satu hak paten untuk alat pembuatan bubur kertas dari kementerian hukum dan HAM (Dirjen HAKI) pada 21 April 2017, dengan nomor IDS000001561

e. Hasil Kajian Social Return On Investment (SROI) atas program selama 2012-2016 berada di rasio 1:7,94, angka tersebut mengindikasikan bahwa untuk setiap Rp. 1,- investasi ditanamkan oleh PHE ONWJ sebagai investor, mengembalikan pengembalian sosial sebesar Rp. 7,94,-. Pengembalian yang dimaksud adalah manfaat yang diperoleh oleh stakeholders.

\section{Hambatan dan Solusi}

Bila ditinjau dari setiap kegiatan yang dijalankan dalam Program 5R++ maka ditemukanlah beberapa hambatan yang dapat diuraikan menjadi 3 bagian yaitu:

a. Tahap Produksi

Hambatan pada tahap produksi terjadi pada output yang dihasilkan oleh mesin antara lain hasil blender kertas kurang maksimal sehingga kertas yang telah diolah mesin masih memiliki tekstur yang padat, selain itu masalah yang terjadi pada mesin blender kertas yang tidak terawat baik. Masalah lainnya yaitu proses pemutaran mesin yang tidak maksimal atau lambat. Untuk itu perlu memaksimalkan mesin pembuat bubur kertas dengan cara melakukan peremajaan mesin dengan pengecatan dan penggantian sparepart yang sudah aus.

b. Tahap Pengembangan

Hambatan selanjutnya terjadi pada tahap pengembangan produksi pembuatan kertas daur ulang dan handycraft yaitu hasil penjualan kertas daur ulang dan handycraft menurun setiap tahunnya, sehingga harus lebih aktif melakukan promosi dan follow up kepada mitra penjualan. 
c. Infrastruktur/Sarana dan Prasarana.

Hambatan terakhir adalah penurunan kualitas infrastruktur seperti meluapnya air selokan di wilayah produksi, atap bocor dan produk yang tidak tertata dengan rapi, sehingga perlu melakukan program pembersihan selokan dan penataan rak penyimpanan hasil produksi.

\section{KESIMPULAN DAN SARAN}

a. PT. Pertamina Hulu Energi ONWJ menjalankan kegiatan Corporate Social Responsibility (CSR) menngunakan empat pilar utama yaitu: pendidikan, kesehatan, lingkungan dan ekonomi. Saat ini PHE ONWJ memiliki tiga program unggulan CD yaitu Program 5R++, Program Master Kasir, dan Program Kapal Kehati GreenThink.

b. Program CSR 5R++ dalam pemberdayaan anak jalanan di wilayah Tanjung Priok dilakukan pada 5 tahap, yaitu 1) pengelolaan limbah kertas; 2) diseminasi keterampilan daur ulang; 3) jaminan kualitas produk dan perlindungan hak kekayaan intelektual; 4) bank sampah; 5) kajian publikasi dan dokumentasi.

c. Hambatan yang dihadapai dalam program CSR 5R++ dikelompokkan menjadi 3 bagian: 1) hambatan dalam tahap produksi (mesin); 2) hambatan dalam pengembangan produksi pembuatan kertas daur ulang dan handycraft; 3) hambatan pada infrastruktur. Adapun solusinya adalah dengan melakukan peremajaan pada mesin, meningkatkan intensitas promosi dan relasi dengan mitra penjualan serta melakukan pembersihan dan renovasi serta pembelian peralatan baru.

\section{DAFTAR PUSTAKA}

Ardianto, Ervinaro. 2011. Metodologi Penelitian untuk Public Relations Kuantitatif dan Kualitatif. Bandung: Remaja Rosdakarya

Cutlip, Scott M, Center dan Broom. 2006. Effective Public Relations. Jakarta: Kencana Prenada Media Group.

Hadi, Nor. 2011. Corporate Social Responsibility. Yogyakarta: Graha Ilmu.

Iriantara, Yosal. 2013. Public Relations. Jakarta: Erlangga

Jefkins, Frank. dan Daniel Yadin. 2003. Public Relations Edisi Kelima. Jakarta: Erlangga.

Katz, Bernard. 1994. Komunikasi Bisnis Praktis. Penerjemah: Soeharsono. Pustaka: Benaman Presindo

Mardikanto, Totok. 2018. Corporate Soial Responsibility (Tanggung Jawab Sosial Perusahaan). Bandung: Alfabeta

Rumanti, Maria Assumpta. 2012. Dasardasar Public Relations (Teori dan Praktik). Jakarta: PT Gramedia Widiasarana Indonesia.

Wibisono, Yusuf, 2007, Membedah Konsep dan Aplikasi CSR. Gresik: Fascho 